\title{
Original
}

\section{Immunohistochemical Investigation of Galectin-3 Expression in Thyroid Follicular Tumors}

\author{
Kenji Iwaku, Nobuyuki Ohike, Takeyoshi Kitayama, \\ Hisashi Hosaka and Toshio Morohoshi
}

\begin{abstract}
We evaluated galectin-3 as a marker of malignancy in thyroid follicular tumors using 29 tumors that had been surgically removed at our facility and related facilities from 1991 to 2005. We also investigated the cell growth fraction (Ki-67-LI). The samples were categorized according to the convention for thyroid cancer: 11 cases of follicular carcinoma ("cancer"), 12 cases of follicular adenoma ("adenoma"), and 6 cases of adenomatous goiter ("hyperplasia"). Immunohistochemistry revealed a high level of galectin-3 expression in 5/11 cancer cases, 3/12 adenoma cases, and 0/6 hyperplasia cases. There was a statistically significant difference between cancer and hyperplasia, but not between cancer and adenoma. Ki-67-LI was $13.4 \%$ in the cancer cases, $4.00 \%$ in the adenoma cases, and $1.78 \%$ in the hyperplasia cases, showing a significant difference between cancer and hyperplasia, as well as between adenoma and hyperplasia. No significant difference was observed between cancer and adenoma $(P=0.051)$. The cancer and adenoma groups with high galectin-3 expression thus showed significantly higher Ki-67-LI than the low galectin-3 expression group. The results suggested that galectin-3 might be useful in distinguishing hyperplastic lesions from neoplastic lesions. Moreover, galectin-3 expression and $\mathrm{Ki}-67-\mathrm{LI}$ together might be useful in determining the biological malignancy of tumors.
\end{abstract}

Key words : galectin-3, thyroid follicular tumors, Ki-67, immunohistochemistry

\section{Introduction}

Thyroid follicular carcinoma ("cancer" is characterized by well-differentiated follicular cells. Unlike papillary thyroid cancer, the absence of cytological findings characteristic of cancer means that thyroid follicular cancer is diagnosed by confirmation of metastasis or the obvious invasion of capsules ${ }^{1.2)}$. If these conditions are not observed, then a diagnosis of adenomatous goiter ("hyperplasia") or follicular adenoma ("adenoma") should be made, although there are some cases of adenoma that show distant metastases upon observation ${ }^{3)}$.

The expression of galectin-3, a glycoprotein belonging to the $\beta$-galactoside binding a reference citation for $\# 3$ family, has been associated with adhesiveness ${ }^{4)}$, malignant alteration $^{5)}$, growth/metastasis, and apoptosis ${ }^{5.7)}$ of cells. It is also useful in distinguishing cancer from adenoma ${ }^{8-11)}$. This study examined the association between galectin-3 expression and

First Department of Pathology, Showa University School of Medicine, 1-5-8 Hatanodai, Shinagawa-ku, Tokyo 1428555, Japan. 
the degree of malignancy as a potential diagnostic tool in cases of thyroid follicular tumor. The cell growth fraction [Ki-67-Labeling Index (LI)] was also examined for comparison.

\section{Samples and Methods}

The study samples comprised 29 thyroid follicular tumors that were surgically removed at our facility and related facilities from 1991 to 2005. The tumors were histologically classified into three types: hyperplasia, adenoma, and cancer, according to the conventional categorization of thyroid cancer ${ }^{1)}$. Galectin-3 expression was evaluated immunohistochemically using the EnVision ChemMate method (DakoCytomation, Kyoto, Japan). Briefly, tumor blocks were deparaffinized before washing in water. Antigen activation was then conducted using $10 \mathrm{mM}$ citrate buffer $\mathrm{pH} 6.0$ at $121^{\circ} \mathrm{C}$ for 15 minutes, followed by TBS washing (50 $\mathrm{mM}$ Tris buffer), and treatment with $3 \%$ hydrogen peroxide for 6 minutes, before further washes in TBS. Endogenous peroxidase was then blocked for 5 minutes, before incubation in an antigalectin-3 primary antibody (Santa Cruz Biotechnology, Inc, Santa

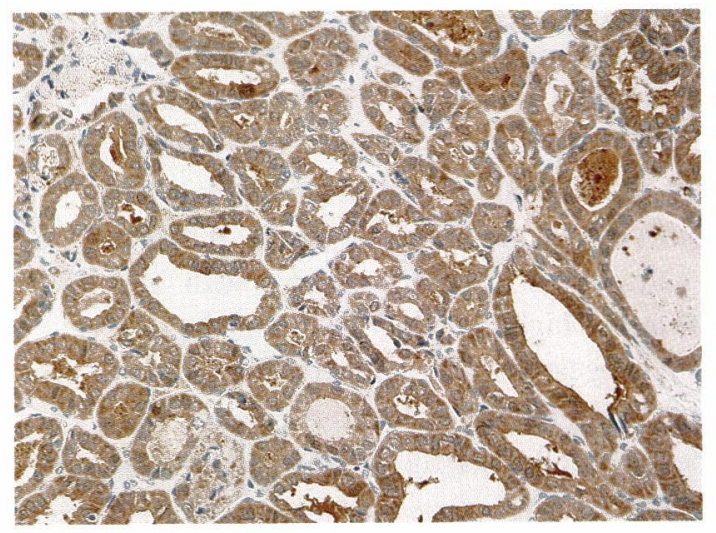

Fig. 1. Galectin-3 positive

Diffusely staining inside the cells $(\times 400$ galectin- 3 )

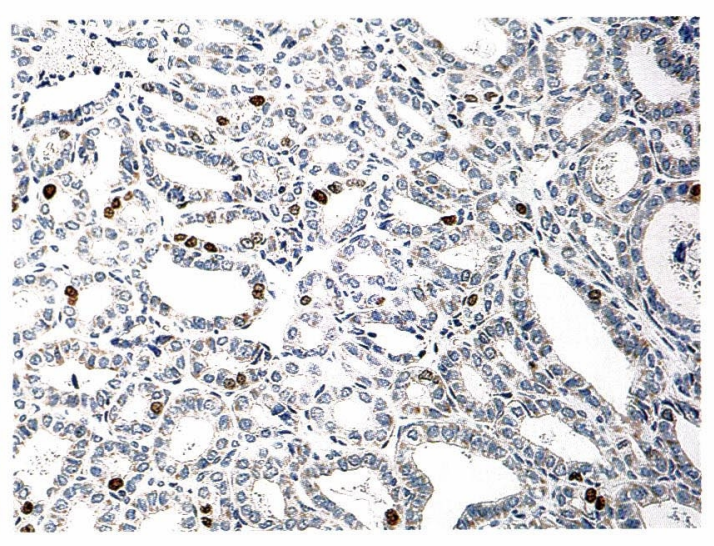

Fig. 2. Ki-67

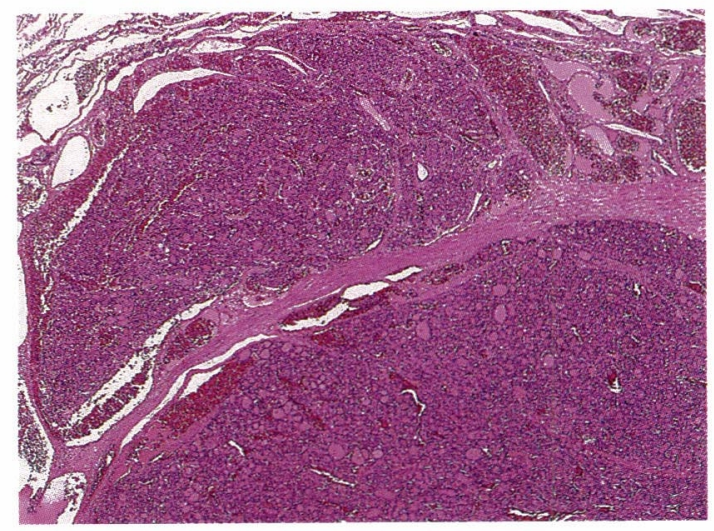

Fig. 3. Follicular carcinoma

Small gland ducts growing densely and some spread out of the capsule $(\times 40 \mathrm{H}-\mathrm{E})$ 
Cruz Ca: sc-20157, 1:100 dilution) for 30 minutes. After washing in TBS, the ChemMate ENVISION polymer reagent response was incubated for 30 minutes, and visualized using DAB. Lastly, counterstaining with hematoxylin was performed. Samples were also immunostained for Ki-67 (DakoCytomation: M7240, 1:50 dilution). High galectin-3 expression was defined by diffuse staining of the entire tumor mass (Fig. 1), while strong expression of Ki-67 was defined by the nucleus being densely colored (Fig. 2). Ten areas containing positive cells were selected to measure the proportion of dense positive cells among all cells at $400 \mathrm{x}$ magnification as the labeling index (LI). A $t$-test and $\chi^{2}$-test were performed for each subject, and a risk rate of less than $5 \%$ was defined as significant.

Table 1.

\begin{tabular}{|c|c|c|c|c|c|c|}
\hline & Age & galectin- $3^{*} 1$ & $\mathrm{Ki}-67-\mathrm{LI}(\%) * 2$ & Metastasis & Follow-up & Outcome \\
\hline \multirow{11}{*}{$\begin{array}{l}\text { Follicular } \\
\text { carcinoma }\end{array}$} & 51 & + & 14.4 & lung, bone & 1 year and 6 months & died from tumor \\
\hline & 44 & + & 31.8 & - & 7 years & alive \\
\hline & 41 & + & 15.5 & - & 3 years & alive \\
\hline & 48 & + & 17.3 & - & 4 years & alive \\
\hline & 63 & + & 21.7 & - & 5 months & alive \\
\hline & 25 & - & 9.9 & - & 5 years and 4 months & alive \\
\hline & 50 & - & 6.6 & bone & 4 years & died from tumor \\
\hline & 71 & - & 10.0 & - & 14 years & alive \\
\hline & 19 & - & 3.9 & - & 4 years and 11 months & alive \\
\hline & 42 & - & 9.9 & - & 1 year and 11 months & alive \\
\hline & 32 & - & 6.9 & - & 5 months & alive \\
\hline \multirow{12}{*}{$\begin{array}{l}\text { Follicular } \\
\text { adenoma }\end{array}$} & 66 & + & 4.5 & - & 12 years & alive \\
\hline & 20 & + & 3.4 & - & 3 months & alive \\
\hline & 58 & + & 17.0 & - & 3 years & alive \\
\hline & 28 & - & 1.7 & - & 1 year & alive \\
\hline & 71 & - & 1.7 & - & 1 year & alive \\
\hline & 65 & - & 2.6 & - & 1 year & alive \\
\hline & 30 & - & 1.3 & - & 2 years & alive \\
\hline & 50 & - & 3.8 & - & 5 months & alive \\
\hline & 35 & - & 1.1 & - & 0 months & alive \\
\hline & 42 & - & 2.3 & - & 2 years & alive \\
\hline & 68 & - & 3.6 & - & 4 years & died of multiple diseases \\
\hline & 47 & - & 5.3 & - & 11 months & alive \\
\hline \multirow{6}{*}{$\begin{array}{l}\text { Adenomatous } \\
\text { goiter }\end{array}$} & 41 & - & 1.5 & - & 0 months & alive \\
\hline & 47 & - & 0.8 & - & 3 years & alive \\
\hline & 30 & - & 3.5 & - & 0 months & alive \\
\hline & 52 & - & 0.8 & - & 1 year & alive \\
\hline & 55 & - & 1.8 & - & 4 years & alive \\
\hline & 65 & - & 2.3 & - & 7 months & alive \\
\hline
\end{tabular}

${ }^{*} 1$ : high expression $(+)$, low expression $(-)$

${ }^{*} 2$ : average positive cell count of 10 views $(\times 400)$ 
Table 2. Expression of galectin-3 in cancer, adenoma and hyperplasia

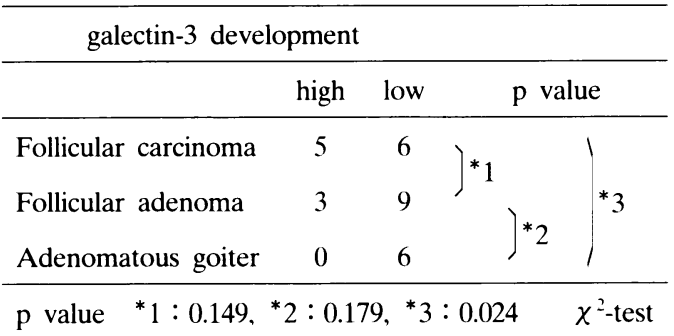

Table 3. Comparison of $\mathrm{Ki}-67-\mathrm{LI}$ in cancer, adenoma and hyperplasia

\begin{tabular}{|c|c|c|c|}
\hline $\mathrm{Ki}-67-\mathrm{LI}$ & & \multicolumn{2}{|c|}{$\mathrm{p}$ value } \\
\hline Follicular carcinoma & 13.4 & \multirow{3}{*}{$\int * 2$} & 1 \\
\hline Follicular adenoma & 4.00 & & $* 3$ \\
\hline Adenomatous goiter & 1.78 & & 1 \\
\hline
\end{tabular}

Table 4. Comparison of $\mathrm{Ki}-67-\mathrm{LI}$ in galectin-3 expression in cancer, adenoma and hyperplasia

\begin{tabular}{llccc}
\hline \multicolumn{5}{c}{ galectin-3 development } \\
\hline & high & low & p value \\
\hline \multirow{3}{*}{ Ki-67-LI } & Follicular carcinoma & 18.433 & 7.46 & 0.006 \\
& Follicular adenoma & 8.3 & 2.6 & 0.038 \\
& Adenomatous goiter & - & 1.78 & - \\
\hline
\end{tabular}

\section{Results}

The tumors were categorized into 11 cases of cancer (Fig. 3), 12 cases of adenoma, and 6 cases of hyperplasia (Table 1). Galectin-3 was expressed in the cytoplasm and the nucleus. High expression levels were observed in 5/11 cancer cases, 3/12 adenoma cases, and $0 / 6$ hyperplasia cases. This result suggested a tendency toward high galectin- 3 expression in cancer, which was significantly different from hyperplasia $(P=0.024)$, but there was no significant difference between cancer and adenoma $(P=0.149)$ (Table 2).

The Ki-67-LI range was $3.9-31.8 \%$ (mean, $13.4 \%$ ) in cancer cases, $1.1-17.0 \%$ (mean, $4.0 \%$ ) in adenoma cases, and $0.8-3.5 \%$ (mean, $1.78 \%$ ) in hyperplasia cases. There were no significant differences seen with $\mathrm{Ki}-67-\mathrm{LI}$, but there was a tendency toward higher growth in cancer than in adenoma $(P=0.051)$. There was, however, a significant difference between cancer and hyperplasia, as well as between adenoma and hyperplasia (Table 3). Taking the two findings together, the high galectin-3 expression group showed a Ki-67-LI of 9.9$31.8 \%$ in cancer (mean, 18.43\%) and $3.4-17.0 \%$ (mean, $8.30 \%$ ) in adenoma, and the low galectin-3 expression group showed $3.9-10.0 \%$ Ki-67-LI (mean, 6.21\%) in cancer, 1.1-5.3\% (mean, 2.60\%) in adenoma, and $0.8-3.5 \%$ (mean, 1.78\%) in hyperplasia. These results showed that the high galectin-3 group had significantly higher growth in both cancer $(P=$ 0.006) and adenoma cases $(P=0.038)$ (Table 4$)$.

\section{Discussion}

Galectin-3 is rarely detected in normal follicular epithelium and adenoma, but has been reported in the cytoplasm and nucleus of cancer cells, prompting suggestions of its value in differentiating adenoma from cancer $^{9-11)}$. However, there were several subsequent reports of 
galectin-3 expression ${ }^{12)}$. In this investigation, high levels of galectin-3 showed no significant difference between cancer and adenoma cases, but expression was low in all cases diagnosed as hyperplasia. We therefore propose that galectin-3 expression could be useful in distinguishing hyperplastic lesions from neoplastic lesions.

An investigation of Ki-67-LI by Katoh et al showed $3.18 \%$ in cancer, $0.9 \%$ in adenoma, and $0.73 \%$ in hyperplasia. The small percentages indicated that the growth ability of Ki-67LI is relatively high in cancer, but these results were not able to be distinguished among the three. In our investigation, the Ki-67-LI was relatively high, and a significant difference was found between some lesions. This difference could have been due to the selection of parts with relatively high densities of Ki-67-positive cells, while Katoh et al selected parts for observation at random ${ }^{13)}$. We consider that our method of selection would more clearly identify differences in growth ability among lesions, although more studies are needed to confirm the validity of this assumption.

In the combined investigation of galectin-3 and $\mathrm{Ki}-67-\mathrm{LI}$, galetin-3 positive cases showed significantly high growth ability in both cancer and adenoma. Ino et al ${ }^{14)}$ reported similar results for cancer and adenoma, and galectin-3 is reported to have a role in tumor growth ${ }^{15)}$. In the present study, there was no significant difference in the expression of galectin-3 and Ki-67-LI between cancer and adenoma. Therefore, galectin-3 and Ki-67-LI alone may not be practical indicators in determining the degree of malignancy in follicular tumors. However, the results on tumor growth ability indicated that examination of both galectin-3 and Ki-67-LI may help in determining biological malignancy.

\section{References}

1) The Japanese Society of Thyroid Surgery: General Rules for the Description of Thyroid Cancer. 6th ed., Kanehara Shuppan. Tokyo (2005) (in Japanese)

2) Raber W, Kaserer K. Niederle B and Vierhapper H: Risk factors for malignancy of thyroid nodules initially identified as follicular neoplasma by fine-needle aspiration: results of a prospective study of one hundred twenty patients. Thyroid 10:709-712 (2000)

3) Kameyama K and Takami H: Topics on pathology of thyroid follicular cancer. Clin Surg 56:1357-1361 (2001) (in Japanese)

4) Inohara $\mathrm{H}$, Akahani $\mathrm{S}$, Koths $\mathrm{K}$ and $\operatorname{Raz} \mathrm{A}$ : Interactions between galectin-3 and Mac-2-binding protein mediate cell-cell adhesion. Cancer Res $56: 4530-4534$ (1996)

5) Raz A, Zhu DG, Hogan V, Shah N, Raz T, Karkash R, Pazerini G and Carmi P: Evidence for the role of 34-kDa galactoside-binding lectin in transformation and metastasis. Int $J$ Cancer 46:871-877 (1996)

6) Akahani S, Nangia-Makker P, Inohara H, Choi Kim HR and Raz A: Galectin-3: A novel antiapoptotic molecule with a functional BH1 (NWGR) domain of Bcl-2 family. Cancer Res 57 : 5272-5276 (1997)

7) Yang RY, Hsu DK and Liu FT: Expression of galectin-3 modulates T-cell growth and apotosis. Proc Natl Acad Sci USA 93: 6737-6742 (1996)

8) Liu FT, Patterson RJ and Wang JL: Intracellular functions of galectins. Biochim Biophys Acta 1572 : 263-273 (2002)

9) Orlandi F. Saggiorato E, Pivano G, Puligheddu B, Termine A, Cappia S, Giuli P and Angeli A : Galectin-3 is a presurgical marker of human thyroid carcinoma. Cancer Res $58: 3015-3020$ (1998)

10) Bartolazzi A, Gasbarri A, Papotti M, Bussolati G, Lucante T, Khan A, Inohara H, Marandino F, Orlandi F, Nardi F, Vecchione A, Tecce R, Larsson O and Thyroid Cancer Study Group: Application of an immunodiagnostic method for improving preoperative diagnosis of nodular thyroid lesions. Lancet $357: 1644-1650$ (2001)

11) Volante M, Bozzalla-Cassione F, Orlandi F and Papotti M: Diagnostic role of galectin-3 in follicular thyroid tumors. Virchows Arch $444: 309-312$ (2004)

12) Ito $Y$ : Molecular mechanisms of thyroid follicular cancer development-recent findings. Endocr Surg 22:90-94 (2005) (in Japanese)

13) Katoh R. Bray CE, Suzuki K, Komiyama A, Henmi A, Kawaoi A, Oyama T, Sugai T and Sasou S: Growth activity in hyperplastic and neoplastic human thyroid determined by an immunohistochemical staining procedure 
using monoclonal antibody MIB-1. Hum Pathol $26: 139-146$ (1995)

14) Ino $H$, Yoshida $A$, Matsuura $H$, Inaba $M$, Nakamura $Y$, Miyagi $Y$ and Hayashi $H$ : On galectin-3 expression in thyroid follicular tumors. Soc Thyroid Surg J 37:68 (2004) (in Japanese)

15) Danguy A, Camby I and Kiss R: Galectins and cancer. Biochim Biophys Acta 1572 : $285-293$ (2002)

[Received December 15, 2006 : Accepted December 22, 2006] 